\title{
HYGIENIC ASSESSMENT OF THE EFFECT OF EMISSIONS FROM MODERN PIG FARMS TO ATMOSPHERIC AIR POLLUTION
}

\author{
Turos O., SlautenkoYe., Mykhina L.
}

\section{ГІГГЕНГИНА ОЦПНКА ВПЛИВУ ВИКИДІВ ВІД СУЧАСНИХ СВИНОКОМПЛЕКСІВ НА ЗАБРУДНЕННЯ АТМОСФЕРНОГО ПОВІТРЯ}

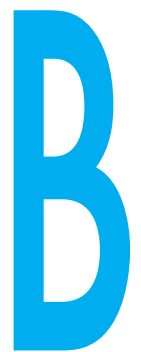

TYPOC O.I., СЛАУТЕНКО Є.Г., МИХІНА Л.І.

ДУ "Інститут громадського здоров'я ім. О.М. Марзєєва

НАМН України", м. Київ

e-mail: e_slautenko@ukr.net

УДК 614.718:636.4:351.777

Ключові слова: атмосферне повітря, свинокомплекси, хімічні речовини, математичне моделювання. останне десятиліття в Україні спостерігається збільшення таких підприємств агропромисловості, як свинокомплекси. Під їх розміщення використовуються пристосовані приміщення та території колишніх сільськогосподарських підприємств різного профілю: тваринницьких ферм, об'єктів обслуговування сільськогосподарської техніки та інших об'єктів з наявними інженерними комунікаціями, які територіально розташовані у межах населених пунктів сільської місцевості. Середня потужність зазначених організованих тваринницьких комплексів становить 10-30 тисяч голів свиней на рік.

Така тенденція призводить до наближення територій свинокомплексів до меж житлової забудови з подальшим недотриманням визначених діючими документами нормативних розмірів санітарно-захисних зон для цих об'єктів [1-3].
Нині на потужних свинофермах України спостерігається позитивна тенденція застосування сучасних автоматизованих сільськогосподарських комплексів 3 утримання та відгодівлі свиней, здійснених за допомогою новітніх технологій, які характеризуються, зокрема, автономними системами припливно-витяжної вентиляції, яка забезпечує оптимальні мікрокліматичні умови утримання худоби, організоване видалення забрудненого повітря із приміщень свинарників витяжними вентиляторами періодичної дії, що, з одного боку, дозволяє більш економно використовувати оптимальні параметри мікроклімату, а з іншого, дозволяє здійснювати викиди забруднюючих речовин періодично

Основними джерелами забруднення на сучасних свинофермах $€$ джерела викидів від будівель свинарників (викидні
ГИГИЕНИЧЕСКАЯ ОЦЕНКА ВЛИЯНИЯ ВЫБРОСОВ ОТ СОВРЕМЕННОГО СВИНОКОМПЛЕКСА НА ЗАГРЯЗНЕНИЕ АТМОСФЕРНОГО ВОЗДУХА

Турос Е.И., Слаутенко Е.Г., Михина Л.И. ГУ "Институт общественного здоровья им. А.Н. Марзеева НАМН Украины", Г. Киев

Состояние проблемы. Рассмотрены особенности загрязнения атмосферного воздуха на границе санитарно-защитной зоны и селитебной зоны выбросами от современных мощных свинокомплексов на примере свинокомплекса с годовой мощностью 30 тысяч голов.

Цель работы: оценить загрязнение атмосферного воздуха выбросами от животноводческих хозяйств на примере хозяйств по содержанию свиней (свинокомплексов) мощностью 30 тысяч голОВ в ГОД.

Материалы и методы. Были использованы библиографический и библиосемантический поиск; проведены натурные инструментальные измерения концентрации загрязняющих веществ в выбросах от стационарных источников загрязнения свинокомплексов и в атмосферном воздухе населенных мест.

Результаты. Установлено, что максимальные концентрации загрязняющих веществ, входящих в состав эмиссий свинокомплекса (сероводород, аммиак, твердые суспендированные частички (ТС4), не превышают предельно допустимый выброс. Средние концентрации загрязняющих веществ в атмосферном воздухе по долям максимально разовой предельно допустимой концентрации (ГДК сероводороду (на расстоянии до 200 м - 2,5 ГДК мр 500 м - 2,4 ГДК веществам (аммиак, ТС4) превышений не было обнаружено.

Выводы. Полученные результаты свидетельствуют об отсутствии загрязнений атмосферного воздуха выбросами аммиака и ТСЧ от свинокомплексов и о загрязнении его сероводородом в концентрациях, превышающих ГДК зависимости от расстояния (200, 500 и 1000 м). Кроме того, полученные результаты дают возможность сокращения нормативных размеров санитарно-защитных зон животноводческих комплексов при условии применения современных производственных технологий содержания и откорма свиней, организации производственных систем вентиляции и технологического процесса содержания скота, позволяющих снизить эмиссию сероводорода до уровня нормативной ГДК

Ключевые слова: атмосферный воздух, свинокомплексы, химические вещества, математическое моделирование.

( Турос О.І., Слаутенко Є.Г., Михіна Л.І. СТАТТЯ, 2018. 
бібліосемантичний пошук. Натурні інструментальні вимірювання рівня концентрації забруднюючих речовин у викидах від стаціонарних джерел забруднення свинокомплексів та в атмосферному повітрі населених місць проводилися за специфічними речовинами відповідного виробництва 3 використанням селективних стандартизованих в Україні аналітичних методів визначення [5-7].

отвори витяжної вентиляції, світлоаераційні ліхтарі тощо), які можна на етапі проектування раціонально розмістити (максимально віддалити від наближеної житлової забудови), які дозволяють знизити ризик для здоров'я населення негативного впливу від забруднення атмосферного повітря.

Окремої уваги при гігієнічній оцінці функціонування об'єктів утримання та відгодівлі свиней потребують умови та місця облаштування гноєсховищ, які $€$ одними з найбільш значимих джерел утворення забруднюючих речовин атмосферного повітря (аміак та сірководень).

Крім того, важливим аспектом функціонування сучасних свинокомплексів $€$ схема організації відгодівлі тварин, а саме: застосування вже готових комбікормів (з мінімальним забрудненням атмосферного повітря часточками пилу) або приготування комбікормів безпосередньо на майданчику свинокомплексу у кормоцехах 3 суттєвим збільшенням інтенсивності процесів пилоутворення та подальшим збільшенням кількості організованих і неорганізованих джерел викидів [3, 4].

у ході дослідження були виділені основні хімічні речовини-забруднювачі атмосферного повітря (сірководень, аміак та тверді суспендовані частинки, недиференційовані за складом (ТСЧ).

Мета дослідження - оцінити забруднення атмосферного повітря викидами від тваринницьких господарств на прикладі свинокомплексів потужністю 30 тисяч голів.

Об'єкт та методи дослідження. Для визначення мети та дизайну дослідження використано бібліографічний та

\section{Примітки:}

значення концентрації забруднювачів.

Відповідно до результатів, викладених у таблиці 1, перевищень концентрацій забруднювачів у викидах щодо ГДВ не виявлено.

Одночасно були проведені вимірювання забруднюючих речовин в атмосферному повітрі на різних відстанях від джерела забруднення (табл. 2).

Так, середні концентрації забруднюючих речовин в атмосферному повітрі за часткою ГДК

$\square$ за сірководнем: на відстані до 200 м - 2,5 ГДК 1,1 ГДК

за аміаком: на відстані до $200 \mathrm{~m}-0,45$ ГДК ГДК 1000 м - 0,1 ГДК

$\square$ за недиференційованим за складом пилом: на відстані до 200 м - 0,89 ГДК 0,72 ГДК ГДК мр.

Аналізуючи наведені у таблиці 2 дані, можна констатувати, що у період спостережень у районі розміщення свинокомплексу реєструвалося помірне забруднення атмосферного повітря за рахунок сірководню.

Оцінюючи клас небезпеки підприємств, визначений за викидами забруднювачів в атмосферу, слід зазначити, що свинокомплекси потужні-

Таблиця 1

Результати вимірювання рівнів викидів забруднюючих речовин із стаціонарних джерел викиду

\begin{tabular}{|c|c|c|c|c|}
\hline $\begin{array}{c}\text { Забруднююча } \\
\text { речовина }\end{array}$ & $\mathrm{CAS}^{*}$ & $\begin{array}{c}\text { Клас } \\
\text { небезпеки }\end{array}$ & \begin{tabular}{|c|} 
Середнє \\
значення \\
концентрацій \\
забруднюючих \\
речовин, \\
мг/м³ \\
\end{tabular} & 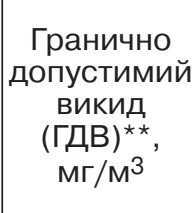 \\
\hline Сірководень & 7783-06-4 & 2 & $\begin{array}{l}0,051-0,084 \\
0,067 \pm 0,009\end{array}$ & 5,0 \\
\hline Аміак & $7664-41-7$ & 4 & $\begin{array}{c}0,36-1,0 \\
0,68 \pm 0,006\end{array}$ & - \\
\hline $\begin{array}{l}\text { Речовини у вигля- } \\
\text { ді суспендованих } \\
\text { твердих частинок, } \\
\text { не диференційо- } \\
\text { ваних за складом }\end{array}$ & - & 3 & $\begin{array}{l}0,56-1,80 \\
1,18 \pm 0,08\end{array}$ & 50,0 \\
\hline
\end{tabular}

CAS* - CAS Registry Number (CASRN, CAS RN, CAS Number,

CAS \#) - номер, під яким хімічна речовина (або суміш речовин) зареєстрована у Chemical Abstracts Service (CAS) [13];

ГДВ** - відповідно до наказу Міністерства охорони навколишнього середовища України від 27.06.2006 р. № 390 [9]. 
HYGIENIC ASSESSMENT OF THE IMPACT OF THE EMISSIONS FROM MODERN PIG COMPLEXES ONAMBIENT AIR POLLUTION Turos O., SlautenkoYe., Mykhina L.

State Institution "O.M. Marzeiev Institute for Public Health of the National Academy of Medical Sciences of Ukraine", Kyiv, Ukraine

Background. Features of ambient air pollution at the border of the sanitary protection zone and the residential area with the emissions from modern powerful pig complexes are considered in the example of the pig complex with an annual capacity of 30 thousands heads.

Objective. We assessed the ambient air pollution with the emissions from livestock farms in the example of the farms for pigs' breeding (pig complexes) with a capacityof 30 thousands heads per year. Materials and methods. We used the method of bibliographic and bibliosemantic search; we performed field instrumental measurements of the concentration of the pollutants in the emissions from stationary sources of contamination of the pig complexes and in ambient air of the settlements.

Results. The maximum concentrations of pollutants in the content of the emissions of pig complex (hydrogensulphide, ammonia, solidsus- pended particles (PM) were established not to exceed the maximum allowable emission.

The average concentrations of the pollutants in ambient air in terms of the maximum single maximum allowable concentration $\left(\mathrm{MPC}_{\text {otm }}\right)$ are exceeded only by hydrogensulfide (at a distance of upto $200 \mathrm{~m}-2.5 \mathrm{MPC}_{\text {otm }}, 500 \mathrm{~m}-2.4 \mathrm{MPC}_{\text {otm }}$, at $\left.1000 \mathrm{~m}-5 \mathrm{MPC}_{\mathrm{otm}}\right)$, no excesses for other substances (ammonia, PM) were detected.

Conclusions. The obtained results testify about absence of ambient air pollution with ammonia and PM emissions from pig complexes and its pollution with hydrogensulphide in concentrations, exceeding $M P C_{\text {otm }}$, depending on distance (200, 500 and $1000 \mathrm{~m})$.

In addition, the obtained results make it possible to reduce the normative sizes of sanitary-and-protective zones of livestock complexes under condition of the use of modern production technologies for the maintenance and fattening of pigs, the organization of the production ventilation systems and the technological process of livestock breeding which reduce the emission of hydrogensulfide to the level of the standard MPC

Keywords: ambient air, pigfarms, chemical substances, mathematical modeling. стю від 30 тис. голів на рік за викидами аміаку і речовинами у вигляді суспендованих твердих частинок, не диференційованих за складом, належать до III класу небезпеки, лише за сірководнем - до II класу небезпеки [10, 12].

Проведення натурних досліджень емісій забруднюючих речовин в атмосферному повітрі у зоні функціонування свинокомплексів потужністю 30 тис. голів показало:

口 середні концентрації забруднювачів, що входять до складу емісій свинокомплексу, не перевищують встановлений ГДВ і становлять за сірководнем 0,067 мг/м³ (0,19 ГДВ),

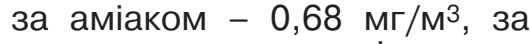
речовинами у вигляді суспендованих твердих частинок, не диференційованих за складом

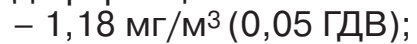

$\square$ середні концентрації забруднюючих речовин в атмосферному повітрі за частками ГДК нем: на відстані до 200 м $0,038 \mathrm{мг} / \mathrm{M}^{3}(2,5$ ГДК мр $), 500 \mathrm{м}$

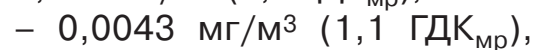
$1000 \mathrm{M}-0,04 \mathrm{мг} / \mathrm{M}^{3}$ (5 ГДК за аміаком: на відстані до 200 м

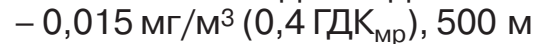
$-0,09 \mathrm{мг} / \mathrm{M}^{3}(0,1$ ГДК мр $), 1000 \mathrm{M}$

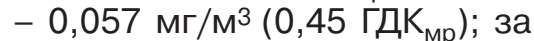
пилом, недиференційованим за складом: на відстані до 200 м
$-0,13 \mathrm{Mг} / \mathrm{M}^{3}(0,89$ гДК $-0,1 \mathrm{Mг} / \mathrm{M}^{3}(0,72$ ГДК $-0,092 \mathrm{мг} / \mathrm{M}^{3}\left(0,69\right.$ ГДК $\left.\mathrm{Mp}_{\mathrm{p}}\right)$.

Результати натурних досліджень атмосферного повітря дозволяють говорити про відсутність перевищення гігієнічних нормативів для атмосферного повітря аміаком та пилом, не диференційованим за складом, та про забруднення його сірководнем у концентраціях, які є більшими за ГДК (200, 500 та 1000 м).

Збільшення концентрацій сірководню в атмосферному повітрі, яке зростає з віддаленням від джерела викиду,

Таблиця 2

Результати вимірювання концентрацій забруднюючих речовин в атмосферному повітрі на різних відстанях від джерела забруднення свинокомплексу

\begin{tabular}{|c|c|c|c|c|c|c|}
\hline \multirow[t]{2}{*}{ Забруднювач } & \multirow[t]{2}{*}{$\begin{array}{l}\text { Клас } \\
\text { небез- } \\
\text { пеки }\end{array}$} & \multicolumn{3}{|c|}{$\begin{array}{c}\text { Концентрації забруднюючих речовин } \\
\text { в атмосферному повітрі на різних відстанях } \\
\text { від джерела забруднення, мг/м³ }\end{array}$} & \multirow[t]{2}{*}{$\begin{array}{l}\mathrm{RfC}^{\star} \\
\mathrm{Mr} / \mathrm{M}^{3}\end{array}$} & \multirow{2}{*}{ 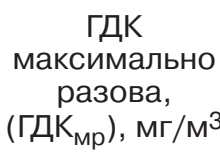 } \\
\hline & & 200 & 500 & 1000 & & \\
\hline Сірководень & 2 & $\begin{array}{c}0,0073-0,07 \\
0,038 \pm 0,0023\end{array}$ & $\begin{array}{c}0,0063-0,035 \\
0,02 \pm 0,004\end{array}$ & $\begin{array}{c}0,0063-0,074 \\
0,04 \pm 0,02\end{array}$ & 0,002 & 0,008 \\
\hline Аміак & 4 & $\begin{array}{l}0,12-0,189 \\
0,15 \pm 0,02\end{array}$ & $\begin{array}{l}0,067-0,12 \\
0,09 \pm 0,022\end{array}$ & $\begin{array}{l}0,098-0,17 \\
0,13 \pm 0,09\end{array}$ & 0,1 & 0,2 \\
\hline $\begin{array}{l}\text { Не диференційований } \\
\text { за складом пил (аерозоль) }\end{array}$ & 3 & $\begin{array}{c}0,098-0,17 \\
0,13 \pm 0,04\end{array}$ & $\begin{array}{l}0,09-0,11 \\
0,1 \pm 0,004\end{array}$ & $\begin{array}{l}0,064-0,12 \\
0,092 \pm 0,08\end{array}$ & 0,3 & 0,5 \\
\hline
\end{tabular}

Примітки: RfC* - референтні (безпечні) концентрації забруднюючих речовин в атмосфері (Review of the reference dose

and reference concentration process EPA/630/P-02/002F, December 2002 Final Report)[14]; 


\section{ЛІТЕРАТУРА}

1. Свинарські підприємства (комплекси, ферми, малі ферми) : ВНТП-АПК-02.05 / Мінагрополітики України. К., 2005. 98 c.

2. Слаутенко Є.Г. Нові інструменти оцінки небезпеки для здоров'я населення від забруднення атмосферного повітря свинокомплексами. Медичні перспективи. 2018. № 1. С. 96-97.

3. Шкуро В.В., Фещенко К.Д., Махнюк В.М., Могильний С.М. Сучасні гігієнічні аспекти функціонування тваринницьких комплексів в Україні. Гігієна населених місць : зб. наук. пр. К., 2009. Вип. 53. С. 37-46.

4. Фаломеев В.3., Саг-

ло О.Ф., Підтереба О.І. Сучасні ефективні технології у свинарстві. Вісник Полтавської державної аграрної академії. 2005. № 3. С. 64-66.

5. КНД 211.2.3.063-98 Метрологічне забезпечення. Відбір проб промислових викидів : Інструкція. С. 10-15. URL : eco.at.ua/downloads/ lab/KND_211.2.3.063-98.doc

$$
\text { 6. РД 50-21 0-80 }
$$

Методические указания по внедрению ГОСТ 17.2.3.02-78 "Охрана природы. Атмосфера. Правила установления предельно допустимых выбросов вредных веществ в атмосферу промышленными предприятиями". М. : Изд-во стандартов, 1980. С. 89-94 ; 105-112.

7. Про затвердження нормативів гранично допустимих викидів забруднюючих речовин із стаціонарних джерел : наказ Мінприроди України № 309 від 27.06.2006 p. URL : http://zakon5.rada.gov.ua/laws /show/z0912-06

8. Ciganek M., Neca J. Chemical characterization of volatile organic compounds on animal farms. Veterinary medicine. 2008. Vol. 53. № 12. P. 641-651.

9. Турос О.І. Можливості використання методології оцінки ризику у попереджувальному та поточному санітарному нагляді. Планування та забудова населених місць: актуальні санітарно-гігієнічні та екологічні проблеми і шляхи їх вирішення : зб. тез доп. наук. -практ. конф. (Київ, 8-9 листопада 2007 р.). К.,
2007. С. 25-26.

10. Державні санітарні правила охорони атмосферного повітря населених місць (від забруднення хімічними та біологічними речовинами) : ДСП201-97/ МОЗ України. К., 1997. 57 c.

11. Рагойша A.A. CAS

Registry Number и справочник Common Chemistry.

Бюллетень химической информации. 2009. № 1. C. 6-8.

12. Review of the reference dose and reference concentration process. EPA/630/P. 02/002F, December 2002 Final Report. 2002. P. 23-28.

REFERENCES

1. Svynarski pidpryiemstva (kompleksy, fermy, malifermy) [Pig Farms (Complexes, Farms, Small Farms) : VNTP-APK02.05] / Ministry of Agrarian Policy of Ukraine. Kyiv ; 2005 : 98 p. (in Ukrainian).

2. Slautenko Ye.H. Medychni perspektyvy. $2018 ; 1$ : 96-97 (in Ukrainian).

3. Shkuro V.V., Feshchenko K.D., Makhniuk V.M. Mohilnyi S.M. Suchasni hihienichni aspekty funktsionuvannia tvarynnytskykh kompleksiv v Ukraini [Modern hygienic aspects of the functioning of livestock complexes in Ukraine]. In : Hihiena naselenykh mists [Hygiene of Settlements]. Kyiv, 2009 ; 53 : 37-46 (in Ukrainian).

4. Falomeiev V.Z., Sahlo O.F. and Pidtereba O.I. Visnyk Poltavskoi derzhavnoi ahrarnoi akademii. 2005 ; 3 : 64-66 (in Ukrainian).

5. КNД 211.2.3.063-98

Metrolohichne zabezpechennia. Vidbir prob promyslovykh vykydiv : Instruktsiia [KND

211.2.3.063-98 Metrological Support. Sampling of the Industrial Emissions : Instruction]. P.10-15. URL eco.at.ua/downloads/lab/KND 211.2.3.063-98.doc

(in Ukrainian).

6. RD50-21 0-80

Metodicheskie ukazaniia po vnedreniiu GOST 17.2.3.02-78

"Okhrana prirody. Atmosfera. Pravila ustanovleniya predelno dopustimykh vybrosov vrednykh veshchestv $v$ atmosferu promyshlennymi predpriyatiyami" [Guidance Document 5021-80 Methodical Instructions on the Implementation of the State Standards 17.2.3.02-78 
"Protection of Nature. Atmosphere. Rules for the Establishment of Maximum Allowable Emissions of Hazardous Substances in the Atmosphere of the Industrial Enterprises"]. Moscow : Izdatelstvo standartov ; 1980 : 89-94; 105-112

(in Russian).

7. Pro zatverdzhennia normatyviv hranychno dopustymykh vykydiv zabrudniuiuchykh rechovyn iz statsionarnykh dzherel : nakaz Minpryrody Ukrainy № 309 vid 27.06.2006. [On the Adoption of the Standards of Maximum Allowable Emissions from the Stationary Sources : Order of the Ministry of Nature of Ukraine № 309, 27.06.2006]. URL :http://zakon5.rada. gov.ua/laws/show/z0912-06 (in Ukrainian).

8. Ciganek M. and Neca J. Veterinary medicine. 2008 ; 53(12) : 641-651.

9. Turos O.I. Mozhlyvosti vykorystannia metodolohii otsinky ryzyku v poperedzhuvalnomu ta potochnomu sanitarnomu nahliadi [Possibilities of the Use of the Methodology for Risk Assessment in Preventive and Routine Sanitary Inspection]. In : Planuvannia ta zabudova naselenykh mists: aktualni sanitarno-hihiienichni ta ekolohichni problem i shliakhy ikh vyrishennia [Planning and Building of the Settlements: Actual Sanitary-and-Hygienic and Ecological Problems and the Ways for their Solution: Conf. Abstracs]. Kyiv, 2007 : 25-26 (in Ukrainian).

10. Derzhavni sanitarni pravyla okhorony atmosfernoho povitria naselenykh mists (vid zabrudnennia khimichnymy ta biolohichnymy rechovynamy) : DSP-201-97 [State Sanitary Rules for the Protection of Ambient Air of the Settlements (from the Contamination with Chemical and Biological Substances) : DSP-201-97]. Kyiv ; $1997: 57 \mathrm{p}$.

(in Ukrainian).

11. Ragoysha A.A. Biulleten khimicheskoy informatsii. 2009 ; $1: 6-8$ (in Russian).

12. Review of the Reference Dose and Reference Concentration Process. EPA/630/P02/002F, December 2002 Final Report. 2002 : 23-28.

Надійшло до редакції 18.01.2018

\section{NATURAL MOVEMENT OF THE POPULATION AND CHILDBEARING ACTIVITY [REEIONAL ASPECT)}

Kalynychenko D.O.

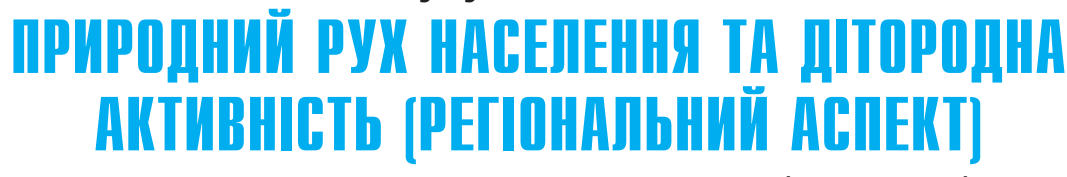

КАЛИНИЧЕНКО Д. О.

Сумський державний

педагогічний університет ім. А. С. Макаренка irinakalinichenko2017@ gmail.com

УДК 614.1+314.8.062.2

Ключові слова: народжуваність, природний приріст, репродуктивний вік, демографічні показники, населення, смертність.

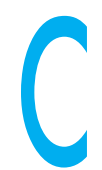
еред регіональних цільових орієнтирів, що пропонуються ВОО3, пріоритетне місце посідає підвищення середньої тривалості життя та рівня благополуччя населення $[1,2]$. Різниця у показниках очікуваної тривалості життя при народженні між країнами 3 найнижчими і найвищими рівнями становить 16 років, показники материнської смертності різняться між країнами у 42 рази, є істотні відмінності у тривалості життя між окреми-

ЕСТЕСТВЕННОЕ ДВИЖЕНИЕ НАСЕЛЕНИЯ И ДЕТОРОДНАЯ

АКТИВНОСТЬ (региональный аспект)

Калиниченко Д.О.

Сумской государственный педагогический университет им. А.С. Макаренко, г. Сумы, Украина

Медико-демографическая ситуация, сложившаяся в последние годы в Украине, свидетельствует о неудовлетворительном состоянии здоровья населения, характеризуется высокими показателями заболеваемости, низкой рождаемостью и высоким уровнем смертности. Цель работы: исследовать современные региональные особенности естественного движения населения и определить типологические группы районов по результатам детородной активности. Материалы и методы исследования. Для анализа демографической ситуации в Украине и Сумской области использовали данные Всеукраинской переписи населения, Государственной службы статистики Украины. Выполнено ранжирование районов Сумской области по показателям естественного прироста (сокращения) населения в 2014-2016 годах. Результаты исследований. Для анализа демографических процессов в области проранжированы трехлетние изменения численности населения каждого районного центра. В ходе исследования установлены районы с относительно благоприятной, напряженной и кризисной демографической ситуацией. Трехлетнее уменьшение численности населения Сумской области происходило преимущественно за счет населения сельской местности $(-3,13)$ по сравнению с населением городских поселений $(-1,09)$.

Установлено, что во всех районах области наблюдается уменьшение общей численности населения, однако факторы демографических процессов разные. Отдельные районы области имеют похожую картину демографических изменений, что позволило по показателям рождаемости и смертности населения выделить четыре типа районов области. Демографическое районирование может служить основой конкретных перспективных медико-социальных мероприятий для указанных регионов. Сумская область относится к регионам с низким показателем среднего количества рожденных детей женщинами в возрасте от 15 лет и старше (2,0-2, 1 ребенка по сравнению с западными областями Украины, где средняя рождаемость более 2,2 ребенка). В период раннего репродуктивного возраста (20-24 года) женщин Украины и Сумской области среднее количество рожденных детей на 1 женщину с высшим образованием составляет 1,09 и 1,06 соответственно. Среди женщин фертильного возраста и в городах, и в селах наиболее распространенной является репродуктивная установка на рождение двух детей.

Ключевые слова: рождаемость, естественный прирост, репродуктивный возраст, демографические показатели, население, смертность.

ㄷ Калиниченко Д. О. СТАТТЯ, 2018. 